\title{
A RELIGIOSIDADE NO TOTALITARISMO E NA FILOSOFIA DA HISTÓRIA MARXISTA
}

The Religiosity in Totalitarianism and Marxist Philosophy of History

Fernanda de Assis Ferreira *

Resumo: Este trabalho trata-se de uma pesquisa sobre como a religiosidade está presente nas visões de mundo modernas. Em Mito e realidade, Mircea Eliade demonstra como os elementos mitológicos permanecem velados nas ideologias e na filosofia da História hodiernas. Para o pensador, os movimentos intelectuais tidos como secularizados, carregam forte influência da religiosidade, existe uma camuflagem do sagrado no profano. O totalitarismo europeu constituiu-se de elementos do milenarismo escatológico, assim como o marxismo. No entanto, este breve escrito pretende ponderar a respeito desta apreciação da filosofia da História de Marx, a fim de desenvolver uma crítica desta suposta presença do mito da Idade do Ouro.

Palavras-chave: Filosofia da História. Totalitarismo. Marxismo. Camuflagem

\begin{abstract}
This paper is related to research on how religiosity is present in the visions of modern world. In Myth and Reality, Mircea Eliade demonstrates how the mythological elements remain veiled ideologies and philosophy of today's history. To the thinker, the intellectual movements seen as secular, carry strong influence of religiosity, there is a camouflage of the sacred in the profane. The European totalitarianism consisted of elements of eschatological millenarianism, as well as Marxism. However, this brief writing intended ponder this assessment of Marx's philosophy of history, in order to develop a critique of this alleged presence of the myth of the Golden Age.
\end{abstract}

Keywords: Philosophy of history. Totalitarianism. Marxism. Camouflage..

* Mestranda em Filosofia pelo Programa de Pós-Graduação em Filosofia da Universidade Federal de Uberlândia. Bolsista CAPES. E-mail: nanda_chimaira15@ hotmail.com

\begin{tabular}{|c|c|l|l|l|l|}
\hline intuitio & $\begin{array}{c}\text { ISSN } \\
1983-4012\end{array}$ & Porto Alegre & Vol.8 $-\mathrm{N}^{\circ} .1$ & $\begin{array}{c}\text { Junho } \\
2015\end{array}$ & p.296-306 \\
\hline
\end{tabular}


Como era de esperar, é sempre a mesma luta contra o Tempo, a mesma esperança de se libertar do peso do 'Tempo morto', do Tempo que destrói e que mata".

Mircea Eliade, Mito e realidade.

\section{Introdução}

O filósofo Mircea Eliade (1907-1986), além disso, importante estudioso da mitologia e historiador das religiões, trata do conceito de religiosidade de forma ímpar. Para o pensador romeno, este elemento sociocultural da humanidade foi se transformando ao longo da própria história e, como uma construção socio-histórica, a religiosidade está presente desde as formas mais arcaicas do pensamento.

É neste propósito que Eliade se ocupa em Mito e realidade. Da divisão de duas formas de vivenciar o mundo a sagrada e a profana, resulta duas espécies de mundo: o cosmos sacralizado e o cosmos dessacralizado; e para cada um destes, existe um tipo de "habitante", respectivamente, o homo

religiosus e o homo moderno. É noção central a tese de que a religiosidade permanece no homem moderno, por mais que este acredite ter "matado Deus" e vivenciar um cosmos dessacralizado.

Deste modo, este trabalho trata-se de uma pesquisa realizada a partir das afirmações de Eliade sobre as camuflagens do sagrado no profano, de como o pensamento mítico foi se modificando ao longo dos tempos, mas não fora extirpado. A argumentação é feita de forma sumária sob algumas afirmações do romeno sobre a religiosidade no totalitarismo e na filosofia da história de Karl Marx. Para isto, dividimos o escrito em três momentos.

$\mathrm{Na}$ primeira parte, de forma preliminar, apresenta-se como Eliade busca compreender o problema da religiosidade em suas obras Mito e realidade e em $O$ sagrado e o profano. Na segunda parte, investigase como a religiosidade está presente em um movimento que se pretende secularizado, o totalitarismo europeu do século XX; recorre-se a obra de Hannah Arendt, Origens do totalitarismo, para esta empreitada, a fim de enriquecer a discussão deste aspecto instigado pela leitura de Eliade. Na terceira parte, analisa-se a censura que o romeno faz à filosofia da história de Marx; para enriquecer a argumentação, são expostas as contribuições de Istvàn Mészáros sobre a teoria da alienação marxiana e de Mauro Castelo Branco de Moura sobre a religiosidade na filosofia práxis. Por fim, temos as considerações finais acerca destas questões.

\section{As camuflagens do Sagrado no Profano, segundo Mircea Eliade}

\begin{tabular}{|c|c|c|c|c|c|}
\hline intuitio & $\begin{array}{c}\text { ISSN } \\
1983-4012\end{array}$ & Porto Alegre & Vol.8 $-\mathrm{N}^{\circ} .1$ & $\begin{array}{c}\text { Junho } \\
2015\end{array}$ & p.296-306 \\
\hline
\end{tabular}


Na obra $O$ sagrado e o profano, Mircea Eliade apresenta o fenômeno do sagrado em toda a sua complexidade. A primeira definição que o autor nos oferece sobre a problemática é que o "sagrado é aquilo que se opõe ao profano". Existem, pois, duas formas de ser no mundo: a do homo religiosus, que vive do mito e está na maior parte de seu tempo próximo a uma hierofania ${ }^{1}$, ou seja, num cosmos sacralizado; e a do homo moderno, que acredita viver apenas dos ditames da razão, vivendo num cosmos dessacralizado, aonde não há nada maior que si próprio, reifica tudo o que toca, visto que nada para ele é sagrado. $\mathrm{O}$ homem ocidental moderno supondo viver no mundo profano se encontra em desconcerto ao deparar-se com o comportamento do homo religiosus, que vivencia o mundo de outra maneira, este consegue transportar-se para outro tempo, embora vivendo no tempo presente. $\mathrm{O}$ autor afirma que: “Encontramo-nos diante do mesmo ato misterioso: a manifestação de algo 'de ordem diferente' - de uma realidade que não pertence ao nosso mundo - em objetos que fazem parte integrante do nosso mundo 'natural', 'profano',"2.

Antecipa-se aqui a incredulidade de Eliade em admitir que o homem moderno consiga romper completamente com os elementos da religiosidade. O propósito do estudioso é compreender numa perspectiva histórico-religiosa a problemática dos mitos. Isto requer analisar a questão desde o início, assim ele faz um estudo de como as sociedades arcaicas tradicionais compreendiam os mitos, por isso em Mito e realidade, reitera que:

Nossa pesquisa terá por objeto, em primeiro lugar, as sociedades onde o mito é ou foi, até recentemente - "vivo" no sentido de que fornece os modelos para a conduta humana, conferindo, por isso mesmo, significação e valor à existência. Compreender a estrutura e a função dos mitos nas sociedades tradicionais não significa apenas elucidar uma etapa na história do pensamento humano, mas também compreender melhor uma categoria dos nossos contemporâneos ${ }^{3}$.

Definir o que é mito é uma difícil incumbência, uma vez que, ao longo dos tempos, houve múltiplas significações para o termo. O pensador romeno, na obra supracitada, percorre os diversos momentos históricos, mas neste rápido estudo não é possível deter-se em todas as definições e perspectivas - histórica, psicológica, teológica e filosófica. Eliade retoma a importância dos mitos nas sociedades arcaicas demonstrando a sua vivacidade, o seu caráter sagrado, de que estes não são uma fábula ou ficção, como interpreta o judeu-cristianismo; seus personagens são seres sobrenaturais

\footnotetext{
${ }^{1}$ Cf. ELIADE, Mircea. O sagrado e o profano: a essência das religiões. São Paulo: Martins Fontes, 2001. O autor define hierofania como uma manifestação do sagrado no mundo profano, o que pode ocorrer através de um objeto, por exemplo, conforme Eliade: "Manifestando o sagrado, um objeto qualquer torna-se outra coisa e, contudo, continua a ser ele mesmo, porque continua a participar do mundo cósmico envolvente. [...] Em outras palavras, para aqueles que têm uma experiência religiosa, toda a Natureza é suscetível de revelar-se como sacralidade cósmica. O Cosmos, na sua totalidade, pode torna-se uma hierofania" (p. 18).

${ }^{2}$ ELIADE, Mircea. O sagrado e o profano: a essência das religiões. São Paulo: Martins Fontes, 2001, p.17.

${ }^{3}$ ELIADE, Mircea. O sagrado e o profano: a essência das religiões. São Paulo: Martins Fontes, 2001, p. 8.
}

\begin{tabular}{|c|c|c|c|c|c|}
\hline intuitio & $\begin{array}{c}\text { ISSN } \\
1983-4012\end{array}$ & Porto Alegre & Vol.8 $-\mathrm{N}^{\circ} .1$ & $\begin{array}{c}\text { Junho } \\
2015\end{array}$ & p.296-306 \\
\hline
\end{tabular}


existentes. Por isso, o mito é uma história real, que relata o que de fato ocorrera, e é através dos ritos que se pode revivê-los, o autor afirma que:

"Viver" os mitos implica, pois, uma experiência verdadeiramente "religiosa", pois ela se distingue da experiência da vida quotidiana. [...] os mitos revelam que o mundo, o homem e a vida têm uma origem e uma história sobrenaturais, e que essa história é significativa, preciosa e exemplar ${ }^{4}$.

É substancial a importância da experiência mitológica para o homem, Eliade sustenta a teoria de que "O homem moderno que se sente e se pretende a-religioso carrega ainda toda uma mitologia camuflada e numerosos ritualismos degradados" 5 . O homem a-religioso, é descendente direto do homo religiosus. Como o sagrado se opõe ao profano, o homem a-religioso tenta se opor ao homo religiosus. Todavia, esta relação não se dá de forma mecânica, conforme o exposto, esta "a-religiosidade", a vivência extrema num mundo totalmente profano, isto é, o cosmos dessacralizado, não é possível, pois,

[...] o homem profano, queira ou não, conserva ainda os vestígios do comportamento do homem religioso, mas esvaziado dos significados religiosos. Faça o que fizer, é um herdeiro. Não pode abolir definitivamente seu passado, porque ele próprio é produto desse passado. É constituído por uma série de negações e recusas, mas continua ainda a ser assediado pelas realidades que recusou e negou. Para obter um mundo próprio, dessacralizou o mundo em que viviam seus antepassados; mas, para chegar aí, foi obrigado a adotar um comportamento oposto àquele que o precedia - e ele sente que este comportamento está sempre prestes a reatualizar-se, de uma forma ou outra, no mais profundo de seu ser 6 .

O homem moderno, que se pretende a-religioso ainda vivencia a experiência religiosa dos mitos em diversas esferas de sua vida e de certos comportamentos, como nas festas de Ano Novo, nos casamentos, no cinema, na literatura, nos movimentos políticos, nos "profetismos sociais", e ainda na psicanálise, que mantém o padrão iniciático. Em todos estes exemplos encontramos comportamentos religiosos camuflados de profano. Está presente em todos eles a disposição em transpor-se do tempo histórico, para outro tempo maior, à maneira arcaica e cosmogônica. Posta esta chave de leitura, doravante, concentra-se a discussão no envolvente convite gestado pela leitura da obra de Eliade, sobre a problemática da mitologia no advento político do totalitarismo.

\section{0 mito escatológico na política moderna: o milenarismo no totalitarismo}

\footnotetext{
${ }^{4}$ ELIADE, Mircea. O sagrado e o profano: a essência das religiões. São Paulo: Martins Fontes, 2001, p. 22.

${ }^{5}$ ELIADE, Mircea. O sagrado e o profano: a essência das religiões. São Paulo: Martins Fontes, 2001, p. 98.

${ }^{6}$ ELIADE, Mircea. O sagrado e o profano: a essência das religiões. São Paulo: Martins Fontes, 2001, p. 98.
}

\begin{tabular}{|c|c|l|l|l|l|}
\hline intuitio & $\begin{array}{c}\text { ISSN } \\
1983-4012\end{array}$ & Porto Alegre & Vol.8 $-\mathrm{N}^{\mathrm{o}} .1$ & $\begin{array}{c}\text { Junho } \\
2015\end{array}$ & p.296-306 \\
\hline
\end{tabular}


Pensar a respeito do homem moderno implica refletir sobre uma sociedade em que foi possível uma das maiores atrocidades da história humana, o evento político do totalitarismo. Eliade afirma que este acontecimento foi uma espécie de milenarismo da era moderna. Este novo tipo de governo ${ }^{7}$, estabeleceuse na União Soviética, como bolchevismo, e na Alemanha, como nazismo.

Estes dois movimentos políticos totalitários anunciaram a profecia do fim deste mundo e o começo de uma nova era, o estabelecimento do Paraíso na Terra. O nazismo difundia a ideologia do racismo, os eleitos para o novo tempo seriam apenas aqueles que se adequavam aos padrões estabelecidos para a "raça ariana". O bolchevismo, por sua vez, embasado numa suposta teoria marxista-leninista, adotou o conceito de lutas de classes como o pressuposto para a propagação de sua ideologia: apenas o proletariado seria capaz de se transpor para a nova era. Para reforçar sua argumentação sobre o milenarismo presente nestes movimentos totalitários, Eliade recorre a um estudioso da temática, assim está exposto em seu texto:

Norman Cohn, o autor do mais recente livro sobre o milenarismo, escreve a propósito do nacional-socialismo e do marxismo-leninismo: "Sob a terminologia pseudo-científica de que um e outro se servem, pode-se reconhecer facilmente uma fantasia cujos elementos lembram singularmente as elucubrações já em curso na Europa medieval. A batalha final e decisiva dos eleitos (sejam eles a 'raça ariana' ou o 'proletariado') contra as hostes do mal (sejam eles os judeus ou a 'burguesia'); um decreto da Providência, pelo qual os Eleitos serão amplamente compensados por todos os seus sofrimentos, com as alegrias do domínio total ou da comunidade total ou de ambos ao mesmo tempo; um mundo purificado de todo o mal e no qual a história irá encontrar sua consumação - eis algumas antigas quimeras que ainda hoje aceitamos"

Para compreender esta consideração do pensador romeno, é necessário recuperar o conceito de "terror da história" que ele propõe em Mito e realidade. Para Eliade, todos os movimentos milenaristas baseiam-se na ideia religiosa do estabelecimento de um Paraíso após um período de provações e de acontecimentos terríveis. O fim de um mundo antigo e o nascimento de um novo implica a noção de que só os “justos" ou "eleitos" estão aptos a habitar este mundo novo, idílico. O mundo antigo, isto é, o mundo que se presencia historicamente, é perverso e injusto, e, por este motivo, deve ser aniquilado. O autor afirma que:

Durante séculos reencontramos, por diversas vezes, a mesma ideia religiosa: Este mundo - o Mundo da História - é injusto, abominável, demoníaco; felizmente,

\footnotetext{
${ }^{7}$ Cf. ARENDT, Hannah. Origens do totalitarismo. Tradução de Roberto Raposo. São Paulo: Companhia das Letras, 2011. A temática do totalitarismo requer as contribuições de Arendt para a sua compreensão, assim ela afirma sobre a novidade deste evento: "Até hoje conhecemos apenas duas formas autênticas de domínio totalitário: a ditadura do nacional-socialismo, a partir de 1938, e a ditadura bolchevista, a partir de 1930. Essas formas de domínio diferem basicamente de outros tipos de governo ditatorial, despótico ou tirânico; e embora tenham emanado, com certa continuidade, de ditaduras partidárias, suas características essencialmente totalitárias são novas e não podem resultar de sistemas unipartidários" (p. 469).

${ }^{8}$ ELIADE, Mircea. Mito e realidade. Tradução de Pola Civelli. São Paulo: Perspectiva, 1972, p.65.
}

\begin{tabular}{|c|c|c|c|c|c|}
\hline intuitio & $\begin{array}{c}\text { ISSN } \\
1983-4012\end{array}$ & Porto Alegre & Vol.8 $-\mathrm{N}^{\circ} .1$ & $\begin{array}{c}\text { Junho } \\
2015\end{array}$ & p.296-306 \\
\hline
\end{tabular}


ele já está em vias de decomposição, as catástrofes já se iniciaram, este velho mundo já começa a fender-se de todos os lados; muito em breve ele será aniquilado, as forças das trevas serão definitivamente derrotadas, os "bons" triunfarão, e o Paraíso será recuperado. Todos os movimentos milenaristas e escatológicos dão provas de otimismo. Eles reagem contra o terror da História com uma força que somente o desespero pode suscitar'.

Este aspecto, das provas de otimismo que o milenarismo dos totalitarismos podem suscitar, exige uma investigação mais aprofundada, como não é a proposta de Eliade, o autor não retoma a questão em seu texto. Todavia, neste exercício reflexivo sobre a problemática da religiosidade presente neste evento político, propõe-se a recuperação das contribuições da análise de Hannah Arendt. A forma singular como a filósofa trata o conteúdo, em Origens do totalitarismo, pode enriquecer a proposição de Eliade.

Arendt evidencia como este novo modelo político, ocasionado pela sociedade de massas do início do século XX, se apresenta como uma ruptura com a tradição. O totalitarismo instaura uma nova atmosfera no âmbito dos assuntos humanos, na qual tudo é possível, a esfera da onipotência humana em que "[...] julgam ser tudo possível a partir da adequada organização das massas num determinado sentido" 10

No volume referido, a autora enumera os elementos que possibilitaram o advento do domínio total: as massas amorfas, o líder, a propaganda, o terror, os campos de concentração, o nacionalismo, o imperialismo, as polícias secretas, as ideologias e uma nova forma de poder. Neste escrito, de modo sucinto, discorre-se apenas sobre algumas destas categorias. Principalmente, sobre a forma como as propagandas utilizaram as ideologias modernas.

Para a pensadora, as propagandas no totalitarismo ganharam uma nova dimensão. É importante referenciar que Arendt afirma que a propaganda é utilizada num momento pré-totalitário, isto é, quando ainda não se estabeleceu no novo país conquistado o governo do poder total, esta é utilizada para angariar mais adeptos para o movimento. Após a conquista, utiliza-se a doutrinação. A propaganda totalitária emprega um cientificismo ideológico. Para os nazistas está mais que comprovado cientificamente que os judeus pertencem a uma raça inferior (depois que o movimento está com força total novos inimigos objetivos foram encontrados, não bastava ser judeu, o simples fato de não pertencer a raça ariana era motivo para o aniquilamento); e para os bolchevistas, estava confirmado cientificamente que a única classe digna de pertencer a uma nova era seria a proletária.

Essas justificações científicas foram apresentadas em forma de Leis, o nazismo era uma "Lei natural”, para qual o mundo deveria necessariamente se encaminhar, utilizou-se uma deformação da teoria da evolução e seleção das espécies de Charles Darwin, o Paraíso seria atingido apenas pela raça superior -

\footnotetext{
${ }^{9}$ ELIADE, Mircea. Mito e realidade. Tradução de Pola Civelli. São Paulo: Perspectiva, 1972, p. 64-5.

${ }^{10}$ ARENDT, Hannah. Origens do totalitarismo. Tradução de Roberto Raposo. São Paulo: Companhia das Letras, 2011, p. 11.
}

\begin{tabular}{|c|c|l|l|l|l|}
\hline intuitio & $\begin{array}{c}\text { ISSN } \\
1983-4012\end{array}$ & Porto Alegre & Vol.8 $-\mathrm{N}^{\mathrm{o}} .1$ & $\begin{array}{c}\text { Junho } \\
2015\end{array}$ & p.296-306 \\
\hline
\end{tabular}


ariana. O bolchevismo seria uma "Lei da história", o comunismo era a finalidade que forçosamente deveria ser alcançada e só o proletariado atingiria este Paraíso (encontra-se aqui, da mesma forma, uma deformidade da teoria marxista).

Arendt esclarece que o motivo do sucesso destas ideologias, está no modo como estas são empregadas pelos seus líderes, são afirmações proféticas, que só serão tornadas possíveis para os séculos vindouros, em suas palavras: "do ponto de vista demagógico, a melhor maneira de evitar discussão é tornar o argumento independente de verificação no presente e afirmar que só o futuro lhe revelará os méritos" ${ }^{11}$. Neste ponto, percebe-se a argumentação de Eliade sobre o terror da história, ideia religiosa corrente no totalitarismo, pode-se fundamentá-la nesta afirmação de Arendt, na qual a filósofa afirma que:

Antes de tomarem o poder e criarem um mundo à imagem da sua doutrina, os movimentos totalitários invocam esse falso mundo de coerências, que é mais adequado às necessidades da mente humana do que a própria realidade; nele, através da pura imaginação, as massas desarraigadas podem sentir-se à vontade e evitar os eternos golpes que a vida e as experiências verdadeiras infligem aos seres humanos e às suas expectativas. A força da propaganda totalitária - antes que os movimentos façam cair cortinas de ferro para evitar que alguém perturbe, com a mais leve realidade, a horripilante quietude de um mundo imaginário reside na sua capacidade de isolar as massas do mundo real ${ }^{12}$.

Conquanto seja envolvente e significativa a discussão desta temática, não é possível nesta sintética pesquisa aprofundar mais a questão. Retoma-se a premissa de Eliade da existência da religiosidade nas teorias modernas da história, e passa-se agora a algumas considerações acerca da noção de história marxiana.

\section{A crítica à religiosidade de Karl Marx}

Neste último item, enceta-se a discussão com a crítica de Eliade, em Mito e realidade, à filosofia da história proposta por Marx. Segundo o pensador romeno o filósofo da práxis retoma um mito escatológico em sua teoria de análise da realidade. O proletariado representa o "papel redentor do Justo", a história encaminha-se para o fim, e o estabelecimento de um novo mundo, afirma Eliade:

Marx retomou um dos grandes mitos escatológicos do mundo asiáticomediterrâneo: o papel redentor do Justo (hoje, o proletariado), cujos sofrimentos são invocados para modificar o status ontológico do mundo. "Efetivamente, a sociedade sem classes de Marx e o consequente desaparecimento das tensões históricas encontram o seu precedente mais exato nos mitos da Idade de Ouro

\footnotetext{
${ }^{11}$ ARENDT, Hannah. Origens do totalitarismo. Tradução de Roberto Raposo. São Paulo: Companhia das Letras, 2011, p.395.

12 ARENDT, Hannah. Origens do totalitarismo. Tradução de Roberto Raposo. São Paulo: Companhia das Letras, 2011, p.402.
}

\begin{tabular}{|c|c|c|c|c|c|}
\hline intuitio & $\begin{array}{c}\text { ISSN } \\
1983-4012\end{array}$ & Porto Alegre & Vol.8 $-\mathrm{N}^{\mathrm{o} .1}$ & $\begin{array}{c}\text { Junho } \\
2015\end{array}$ & p.296-306 \\
\hline
\end{tabular}


que, segundo muitas tradições, caracterizam o começo e o fim da História. Marx enriqueceu esse mito venerável de toda uma ideologia messiânica judeu-cristã: de um lado, o papel profético e a função soteriológica que atribui ao proletariado; de outro lado, a luta final entre Bem e o Mal, que pode ser facilmente comparada ao conflito apocalíptico entre Cristo e Anticristo, seguido da vitória definitiva do primeiro. É de fato significativo que Marx retome por sua conta a esperança escatológica judeu-cristã de uma finalidade absoluta da História; nesse ponto ele se afasta dos outros filósofos historicistas (por exemplo, Croce ou Ortega y Gasset), para os quais as tensões da história são consubstanciais da condição humana e não podem, portanto, jamais ser completamente abolidas" ${ }^{13}$.

Há várias abordagens possíveis para o enfrentamento desta crítica à filosofia da história marxista, porém, apresenta-se neste trabalho uma aversão à incompreensão de Eliade ao discorrer que existe este tipo de teleologia na teoria marxiana. De começo, basta o entendimento de que em Marx não há uma teleologia da história que pressuponha o fim da própria história. Não há uma teleologia teológica em Marx.

A interpretação de que existe uma teleologia teológica em Marx advém de uma interpretação reducionista, o economicismo, isto é, o determinismo econômico. Esta confusão implica na negação final da história. As ações humanas só podem ser compreendidas de maneira sócio-histórica. Se existe uma teleologia esta não pode ser a-histórica, ou seja, uma predição, assim afirma István Mészáros:

Na concepção de Marx, a história permanece aberta de acordo com a necessidade ontológica específica da qual a teleologia humana automediadora é parte integral: pois não pode haver nenhum modo de predeterminar as formas e modalidades da "automediação" humana (cujas complexas condições só podem ser satisfeitas no curso dessa mesma automediação), exceto reduzindo arbitrariamente a complexidade das ações humanas à crua simplicidade das determinações mecânicas. Nunca se pode alcançar um ponto na história no qual seja possível dizer: "agora a substância humana foi plenamente realizada". Pois uma tal delimitação privaria o ser humano de seu atributo essencial: seu poder de "automediação" e "autodesenvolvimento"14.

Para o autor húngaro, a teoria da alienação de Marx é a sua filosofia da história. A emancipação humana, proposta (não prevista) por Marx em sua obra não é uma escatologia, segundo Mészáros: "Na visão de Marx - que não pode reconhecer nada como absolutamente final - não pode haver lugar para uma idade do ouro utópica, nem 'ali na esquina', nem a uma distância astronômica. Tal idade do ouro seria o fim da história, e com isso o fim do próprio homem "15. O escritor reconhece que há críticos e "seguidores" que o identificam como um profeta, no entanto, Marx não fez predições de um Paraíso, o fato é que muito do que se critica neste pensador é retirado de frases vagas, soltas, que realmente remetem

${ }^{13}$ ELIADE, Mircea. Mito e realidade. Tradução de Pola Civelli. São Paulo: Perspectiva, 1972, p. 158.

${ }^{14}$ MÉSZÁROS, István. A teoria da alienação em Marx. Tradução de Isa Tavares. São Paulo: Boitempo, 2006, p. 111.

${ }^{15}$ MÉSZÁROS, István. A teoria da alienação em Marx. Tradução de Isa Tavares. São Paulo: Boitempo, 2006, p.221.

\begin{tabular}{|c|c|c|c|c|c|}
\hline intuitio & $\begin{array}{c}\text { ISSN } \\
1983-4012\end{array}$ & Porto Alegre & Vol.8 $-\mathrm{N}^{\mathrm{o}} .1$ & $\begin{array}{c}\text { Junho } \\
2015\end{array}$ & p.296-306 \\
\hline
\end{tabular}


a este sentido. O filósofo sequer fez uma teoria do comunismo, sua teoria é de análise das contraditórias relações do capitalismo.

A filosofia da história marxiana entendida como uma teoria da alienação nos remete a compreender que não é possível uma desalienação total dos homens, uma espécie de Paraíso. Entretanto, é necessário o conhecimento de que a alienação não é uma tensão inseparável da existência humana. E, mais, para Mészáros, "a história é uma dimensão do homem, mas a alienação não pode ser uma dimensão fundamental da história", por isso, o comentador marxista afirma que "O capitalismo não se caracteriza simplesmente pela alienação e reificação, mas também pela maximização da tendência à alienação, a tal ponto que é a existência mesma da humanidade que está agora em jogo" 16 .

Outra abordagem de grande valia para a temática da religiosidade em Marx, é o livro do professor Mauro, Os mercadores, o templo e a filosofia: Marx e a religiosidade. Neste escrito, o estudioso argumenta que Marx inaugura seu discurso com uma crítica à religiosidade. A religiosidade é um dos constitutivos do ser social para Marx ${ }^{17}$, e isto tem relevância no pensamento do filósofo.

Nesta abordagem o autor defende que existe uma "tríade fetichóide" (mercadoria, dinheiro e capital), que incorporam elementos de religiosidade na atual sociedade. $\mathrm{O}$ dinheiro manifesta-se como algo sagrado, embora seja profano. Existe todo um simbolismo misterioso a respeito dele; para alguns ele têm virtudes demoníacas, ao passo que, para outros, virtudes benfazejas. O capital é uma espécie de divindade com a função em que valor gera mais valor, e a ele todos os homens estão subsumidos, inclusive aqueles que dele estão de posse. Sobre o mercado, Mauro afirma que:

[...] sua existência depende de uma ritualística reiterativa comparável à dos cultos religiosos. O mercado só se mantém mediante o ritual de compra e venda de seus devotos, que seguem monótona e repetitivamente certos procedimentos litúrgicos. Qualquer iniciativa, que ignore seus cânones, corre o risco de heresia e o infiel que ouse frontalmente contestá-lo, será castigado com a ruína; a providência, neste último caso, certamente lhe fechará as portas. A submissão a esse ente, absolutamente impessoal e abstrato, é um requisito indispensável para o êxito na vida social; qualquer pragmática eficaz, que se ancore apenas na imediatidade, deve curvar-se perante essa evidência ${ }^{18}$.

\footnotetext{
${ }^{16}$ MÉSZÁROS, István. A teoria da alienação em Marx. Tradução de Isa Tavares. São Paulo: Boitempo, 2006, p. 228.

${ }^{17}$ Cf. MARX, Karl. Prefácio de 1859. In: Para a crítica da economia política. São Paulo: Abril Cultural, 1978. p. 127-132. (Os Pensadores). No Prefácio de 1859, Marx evidencia a sua teoria da correspondência entre estrutura e superestrutura numa dada sociedade, ele afirma que: "Com a transformação da base econômica, toda a enorme superestrutura se transforma com maior ou menor rapidez. Na consideração de tais transformações é necessário distinguir sempre entre a transformação material das condições econômicas de produção, que pode ser objeto de rigorosa verificação da ciência natural, e as formas jurídicas, políticas, religiosas, artísticas ou filosóficas, em resumo, formas ideológicas pelas quais os homens tomam consciência deste conflito e o conduzem até o fim" (p. $130)$.

${ }^{18}$ MOURA, Mauro Castelo Branco de. Os mercadores, o templo e a filosofia: Marx e a religiosidade. Porto Alegre: EDIPUCRS, 2004, p. 300-1.
}

\begin{tabular}{|c|c|c|c|c|c|}
\hline intuitio & $\begin{array}{c}\text { ISSN } \\
1983-4012\end{array}$ & Porto Alegre & Vol.8 $-\mathrm{N}^{\circ} .1$ & $\begin{array}{c}\text { Junho } \\
2015\end{array}$ & p.296-306 \\
\hline
\end{tabular}


A religiosidade tem grande destaque na crítica à sociedade burguesa. Se cada sociedade tem uma superestrutura que corresponde ao seu desenvolvimento, toda religiosidade está situada historicamente. O mundo moderno capitalista, assim como não superou o processo de reprodução social "alienatório", não superou a religiosidade. Sobre a famosa afirmação de Marx de que a "religião é o ópio do povo", que foi adotada pelo conhecido "socialismo real" como uma norma de conduta, adverte-se que Marx reconhece o caráter de alienação presente nela - pois ela corrobora para a manutenção de um mundo de usurpação e exploração, prometendo um mundo melhor após esta vida - entretanto, o filósofo reconhece a importância da religiosidade para a humanidade, e que ela não pode ser extirpada de forma automática, conforme Moura:

Todavia, não há decreto que possa extinguir, de um canetaço, a religiosidade, sem levar com ela as condições sociais que a fizeram emergir, ainda que, de modo impreciso, a religiosidade, para Marx, já nesse primeiro momento, não seja um mero epifenômeno ideológico superficial, cujo simples esclarecimento permitisse superar ${ }^{19}$.

Por fim, voltamos à concepção de Eliade, que parece exprimir a mesma ideia, sob o aspecto da permanência da religiosidade no homem moderno, embora esta apareça camuflada de profana, em suas palavras: "O pensamento mítico pode ultrapassar e rejeitar algumas de suas expressões anteriores, tornadas obsoletas pela História, pode adaptar-se às novas condições sociais e às novas modas culturais, mas ele não pode ser extirpado" 20 .

\section{Considerações finais}

Neste escrito, refletiu-se sobre a concepção de religiosidade em Mircea Eliade. Buscando compreender a sua conceituação de que a religiosidade, o pensamento mítico, está presente em toda a história humana sob diferentes formas, depreende-se que o homem moderno ainda conserva em seu modo de existir no mundo formas de viver "religiosas". O homem moderno camufla o sagrado de profano. Embora não admita, por vezes, ele busca viver de forma sagrada neste cosmos dessacralizado. Como já exposto, o homem moderno busca sair de seu momento histórico e viver em outra dimensão histórica em diversos atos seus, como nas vivências estéticas, na própria religião, na adesão a certas ideologias, na participação política, e de tantas outras formas.

Eliade, com este modo de ver a religiosidade, instiga o leitor a pensar o problema em vários âmbitos. Mesmo que de modo introdutório, buscou-se relacionar esta concepção para a compreensão da

\footnotetext{
${ }^{19}$ MOURA, Mauro Castelo Branco de. Os mercadores, o templo e a filosofia: Marx e a religiosidade. Porto Alegre: EDIPUCRS, 2004, p.92.

${ }^{20}$ ELIADE, Mircea. Mito e realidade. Tradução de Pola Civelli. São Paulo: Perspectiva, 1972, p 152.
}

\begin{tabular}{|c|c|c|c|c|c|}
\hline intuitio & $\begin{array}{c}\text { ISSN } \\
1983-4012\end{array}$ & Porto Alegre & Vol.8 $-\mathrm{N}^{\mathrm{o}} .1$ & $\begin{array}{c}\text { Junho } \\
2015\end{array}$ & p.296-306 \\
\hline
\end{tabular}


religiosidade presente no advento do totalitarismo, o que permite esclarecer o fenômeno em novas perspectivas. E, também, na presença da religiosidade na teoria da história proposta por Marx, a qual pode ser abarcada sob vários aspectos, o que de modo algum fora esgotado nestas poucas linhas. No entanto, este exercício filosófico permitiu a compreensão de que a crítica de Eliade à escatologia da filosofia marxiana da história, como uma teleologia teológica deve ser reparada. Quanto à presença da religiosidade na forma como Marx analisa as relações da sociedade capitalista, esta merece destaque, e é fonte de inspiração para vários trabalhos e, mais ainda, é uma temática de grande importância para a compreensão da própria filosofia marxiana.

\section{Referências}

ARENDT, Hannah. Origens do totalitarismo. Tradução de Roberto Raposo. São Paulo: Companhia das Letras, 2011. ELIADE, Mircea. Mito e realidade. Tradução de Pola Civelli. São Paulo: Perspectiva, 1972. . O sagrado e o profano: a essência das religiões. São Paulo: Martins Fontes, 2001.

Marx, Karl. Prefácio de 1859. In: Para a crítica da economia política. São Paulo: Abril Cultural, 1978. p. 127-132. (Os Pensadores).

MÉSZÁROS, István. A teoria da alienação em Marx. Tradução de Isa Tavares. São Paulo: Boitempo, 2006.

MOURA, Mauro Castelo Branco de. Os mercadores, o templo e a filosofia: Marx e a religiosidade. Porto Alegre: EDIPUCRS, 2004.

Recebido em: 26/09/2014

Aprovado para publicação em: 05/05/2015

\begin{tabular}{|c|c|l|l|l|l|}
\hline intuitio & $\begin{array}{c}\text { ISSN } \\
1983-4012\end{array}$ & Porto Alegre & Vol.8 $-\mathrm{N}^{\mathrm{o}} .1$ & $\begin{array}{c}\text { Junho } \\
2015\end{array}$ & p.296-306 \\
\hline
\end{tabular}

